\title{
Individual and work related factors associated with symptoms of musculoskeletal complaints. II Different risk factors among sewing machine operators
}

\author{
R H Westgaard, T Jansen
}

\begin{abstract}
Individual and work related risk factors in the development of occupational musculoskeletal complaints were studied in a group of 210 female production workers, mainly sewing machine operators. Another group of 35 female employees performing secretarial or laboratory duties were also included. The production workers had significantly higher symptom scores with respect to self reported musculoskeletal complaints than the group with more varied work tasks for the head, neck, shoulders, and arms, but not for the low back, hips, and the lower extremities. No significant differences were found in symptom level between geographically separate groups of production workers with similar work tasks. The main individual risk factor identified in this study was the experience of previous, similar symptoms in the same body region, but this factor only accounted for $2-3 \%$ of total variance in symptom score for the neck and shoulders. Other individual factors of importance for symptoms in the neck and shoulders were "signs of psychological problems" and "tendency of muscle tension," but these only account for about $1 \%$ of total variance in symptom score. Symptoms in the head and low back showed complex relations with individual parameters.
\end{abstract}

It has long been recognised that workers with predominantly repetitive work tasks, or those maintaining fixed postures for long periods, have an

Division of Organisation and Work Science, the Norwegian Institute of Technology, Trondheim, Norway

R H Westgaard

National Institute of Occupational Health, Department of Physiology, PO Box 8149 Dep, Oslo 1, Norway

$T$ Jansen increased risk of developing work related musculoskeletal illnesses. ${ }^{12}$ Most of these studies have focused on the detrimental health effects of the work situations, whereas little attention has been given to the considerable heterogeneity in response to the work strain. Work tasks considered to be a major factor in early retirement of some workers does not, apparently, affect other workers at all. A better understanding of factors underlying this diversity of responses may help in the design of the work stations, perhaps by including some of the wider work organisational and psychosocial issues in the planning.

The presence of individual risk factors in the development of occupational musculoskeletal illnesses is only sparsely documented. Kilbom ${ }^{3}$ reported that low muscle strength was a risk factor for development of shoulder, neck, and arm disorders in a group which frequently exerted high level external forces. This was not the case for another group exposed to low level postural loads. Psychosocial factors in the work environment or at home have been suggested as risk factors. ${ }^{4}$ The psychological state of the worker is another possible risk factor. In Norway a large fraction of workers receiving disability allowances due to chronic tension myalgia suffer from elements of psychiatric illnesses. ${ }^{6}$ Muscle pain also appears to correlate with specific psychological states or traits. $^{7}$

The present study of risk factors contributing to the development of occupational musculoskeletal disorders is based on interviews of production workers in a clothing company, mostly sewing machine operators. As well as symptom state, ${ }^{8}$ information relating to the life situation of the subject was included. The operators had a mean static load in the trapezius muscles of about $5 \%$ of maximal voluntary contraction, and recorded frequent sick leaves due to musculoskeletal injuries. ${ }^{9}$ It is also generally known that these work tasks are associated with a high rate of musculoskeletal injuries, particularly in the shoulder and neck region..$^{10-15}$ The study therefore allowed us to look for factors modulating the health effects of a work load known to be detrimental to the health of a large fraction of the workers.

Most studies showing an association between 
individual risk factors and the development of musculoskeletal injuries use study populations with low or unspecified work loads. A low risk of work related musculoskeletal complaint may allow individual risk factors to show up more clearly, and it was of interest to see if individual risk factors remained important when the aetiology was probably dominated by postural muscle strain at the workplace.

\section{Methods}

The study is based on 210 production workers and 35 other employees with varied work tasks, all women, employed by a Norwegian clothing company. The 35 comprised all available female employees not performing production work tasks. About half the production workers (118) were sewing machine operators producing thermal clothing at three towns, Moss (18 subjects), Halden (44 subjects), and Rjukan (39 subjects), and one village, Tinn (17 subjects) in southern Norway. Six subjects at Halden and one at Rjukan were combining this work with other duties, such as other production work or supervisory duties. The remaining workers were all employed at Moss. Two groups of 34 and 25 subjects performed sewing and welding tasks in the production of off shore survival suits. The final 26 production workers were performing various sewing tasks not strictly coinciding with the above group definitions. The nonproduction ("office") group consisted of 31 subjects performing general office work, mainly secretarial duties at the company headquarters, or a combination of laboratory and office work (four subjects). The work situation for all members of the office group allowed considerable flexibility in alternating between different work tasks, although prolonged periods with typing might occur.

The sewing machine operators adopted a seated posture with the lower arms moderately extended in front of the body. The table surface was adjustable for height and was usually placed just below elbow height. Thus the external load on the neck and shoulders was quite low in static biomechanics terms, but the need for continuous use of the arms over large working areas made these work situations strenuous. Some differences existed in the type of thermal clothing produced at the different departments: mittens were produced in Halden, other small garments in Tinn, and large garments in Rjukan whereas the production in Moss consisted of large garments including prototypes of new designs. Sewing operations in the production of offshore survival suits were similar to those of thermal clothing, except that the garments were heavier. Welding operations required positioning of material on the welding machine every one to two minutes, but the arms were resting while the welding took place. The welding task therefore
Table 1 Subject related parameters in the questionnaire

Work task
Work time
Geographical location
Health related variables
Musculoskeletal pain before employment
Musculoskeletal pain in present work situation
Cause of musculoskeletal pain
Specific work task(s) associated with pain
Use of pain relieving drugs
Medical consultation due to pain (date)
Short term sick leave due to pain (date)
Long term sick leave due to pain (date)
Physical therapy (No last year and in total)
Background variables

Age

Background variables

Marital state

No of children

Living condition

Work load at home

Effort invested in leisure time activities

Relationship to close family

Signs of psychological problems

Tendency to muscle tension

Economic situation

Physical activities/training programmes

allowed regular rest pauses, at least with regard to movement of the arms.

Symptoms of pain or discomfort were scored for eight body regions (the dorsal aspects of the head, neck, shoulders and upper arms, lower arms, low back, hip, thighs, and knees and ankles) according to the system described in the preceding paper. ${ }^{8}$ Apart from data on symptoms, three categories of questions were included in the questionnaire: (1) related to work task, (2) related to symptoms, and (3) related to individual factors (table 1). The variables related to work task gave factual information on geographical location, work task, and hours at work. Variables related to symptoms included symptoms of pain before present work situation (as a general question), whether the respondent related painful experiences to her working conditions, whether specific work tasks were particularly strenuous, use of medication to relieve pain, long term or short term sick leave due to pain, treatment by physical therapy, and date of last medical consultation due to pain (verified by medical records). Finally, the individual factors included age, marital state, number of children, living conditions, work load at home, leisure time activities, relationship to close family, signs of psychological problems, self reported tendency of muscle tension, economic situation, and amount of physical exercise.

Most parameters that were not factual information were scored on a three point scale indicating low, intermediate, and high values. The scoring was performed by the interviewer, after a discussion with the respondent when the content of the different questions were explained. All interviews were carried out by a consultant of physical medicine (TJ). The 
parameter "signs of psychological problems" was scored on the basis of the interviewer's impression of the subject after detailed questioning. High values would indicate recurring depression or anxiety, often related to specific events. Information on psychological problems was recorded before the recording of pain symptoms. The scoring of this parameter was performed about two months later on the basis of the recorded information, when there was no recollection of the pain symptoms. If in doubt the parameter value was also considered by RHW.

The parameter "relationship to close family" was used as an indicator of the general psychosocial life situation of the respondent. The study did not include an indicator of psychosocial situation at work, but the impression when carrying out the interviews was that work satisfaction in general was high. The parameter "tendency to muscle tension" was the response to a question as to whether the subject had noticed herself generating muscle tension not part of a purposeful movement. The question was included half way through the series of interviews as several of the first respondents volunteered this information. Consequently many "missing" values were recorded. The measurement of amount of physical exercise was related to the level of condition training (jogging, swimming, handball). The parameter "economic situation" was quantified on the basis of need to work due to financial strain.

Statistical analysis was performed as a generalised test of differences in level of symptoms at different body locations with respect to the different independent variables. The Kruska-Wallis test was used in the univariate analysis. When comparing frequencies the Fisher's exact test was applied. In the multivariate analysis linear regression models with backward variable selection were used. All statistical analyses were performed with the SAS statistical package and $p<0.05$ was taken to indicate statistical significance.

\section{Results}

SYMPTOMS OF PAIN OR DISCOMFORT DURING WORK

In response to the general question on experience of pain or discomfort at work, 200 of $210(95 \%)$ production workers answered in the affirmative and $156(74 \%)$ were convinced that their problem was related to their working conditions. These percentages were clearly lower among the 35 subjects in the office group in which $25(71 \%)$ reported pain or discomfort at work and 16 of these $(46 \%)$ were convinced that the problem was due to working conditions. Subjects convinced of a causal relation between their subjective symptoms and working conditions were able to identify specific work tasks that, in their opinion, were associated with the development of such symptoms.
Both the production workers and the office group recorded a high rate of medical consultations due to pain or discomfort in the musculoskeletal system (70\% and $51 \%$ respectively). The main difference between the two groups was the outcome of the consultation; $76 \%$ of the production workers recorded a subsequent sick leave compared with $39 \%$ for the office group. The remaining patients of the office group usually received physical therapy while carrying on working $(61 \% v 16 \%$ for the production workers). This difference may be due to the more flexible work situation of the office group, and also to less symptoms at the time of the medical consultation, ${ }^{8}$ which would reduce the need of sick leave to cope with their complaint.

\section{SYMPTOMS OF PAIN OR DISCOMFORT RELATED TO THE} WORK SITUATION

Figure 1 shows the mean symptom score of different body regions for production and office workers. The symptom scale is based on two parameters, intensity and frequency of symptoms, which are added to produce a combined symptom score ranging from no symptoms (a score of 0 ) to daily occurrence of severe symptoms (a score of 6 ; $\mathrm{see}^{8}$ ). The individual differences and the high frequency of symptoms in the study population made it advantageous to treat the symptom scores as continuous parameters rather than to

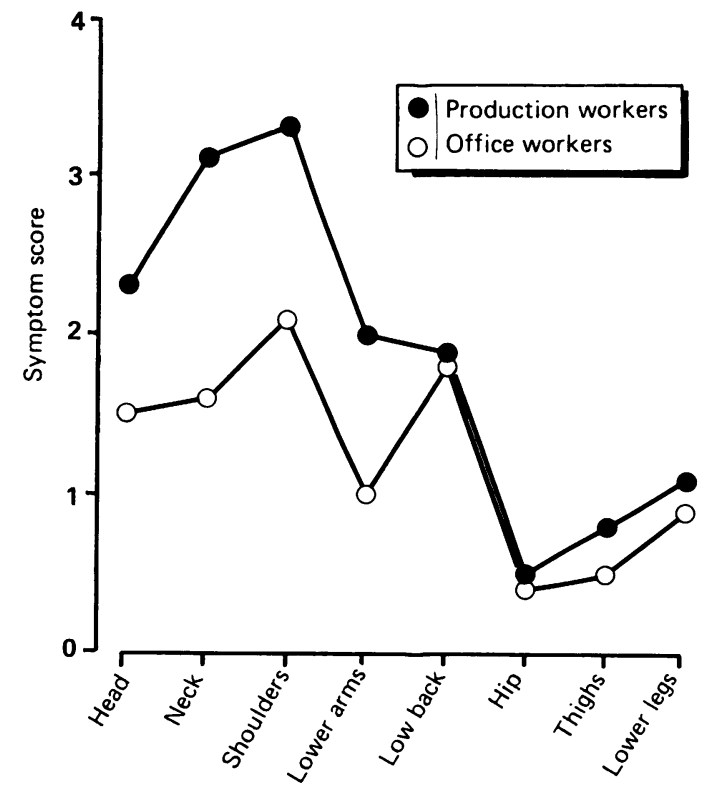

Figure 1 Mean symptom score at different body locations for 210 production workers mainly operating sewing machines and 35 office workers mainly performing secretarial duties. Symptom score is the sum of an intensity score (0-4) and a frequency score $(0-2)$. See text ${ }^{8}$ for details on the scoring system. 


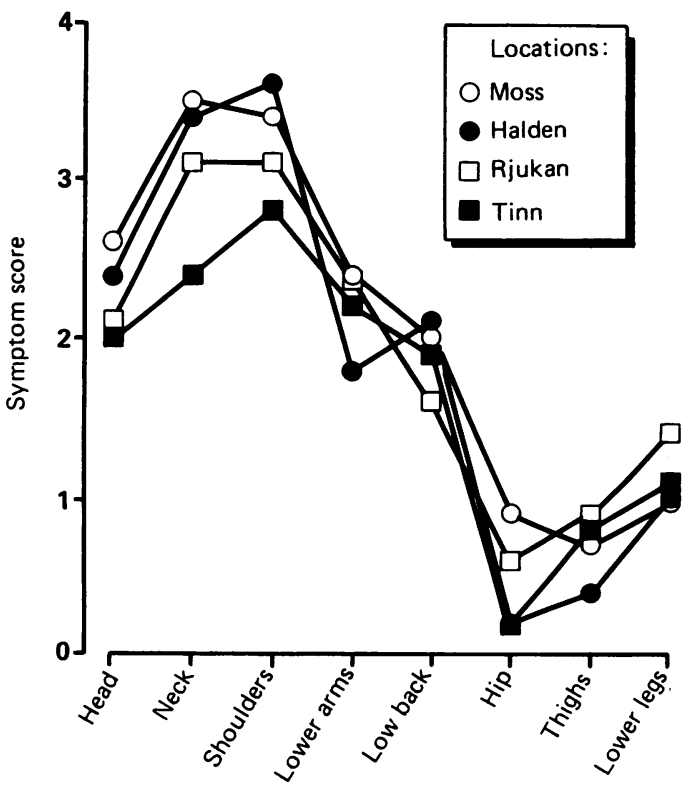

Figure 2 Mean symptom score at different body locations for four groups of sewing machine operators producing thermal clothing at four geographically separate locations in southern Norway.

consider the symptom frequencies. The symptom values of the different body regions are joined by lines to produce a continuous curve, a "body profile of pain," emphasising the most affected body regions. Seventy one per cent of the production workers reported a symptom score of 3 or higher for the shoulder region compared with $41 \%$ for the office group.

The reported symptoms were mostly affecting the neck and shoulders, less so the dorsal aspects of the head, the lower arms, and the low back. Few workers had problems with the hip and lower extremities. The distribution of symptoms corresponded to the location of work strain: shoulders and arms were in continuous use when performing the work tasks, generating static muscle loads. The lower arms and hands were at risk due to the need of continuous control of the garment when performing the twisting and turning movements. The forward leaning seated posture probably strained the low back. Symptoms in the dorsal aspects of the head often relate to shoulder and neck tension as several neck and shoulder muscles arise from this area.

The symptom scores of the head, neck, shoulders, and lower arms were clearly lower for the office group relative to the production workers ( $p$ values from 0.006 to $<0.001$ ). By contrast, no difference was found in symptom score for the low back and the lower extremities indicating no effect (or a similar effect) of working conditions with regard to reported symptoms in these body regions.

The four geographically separate groups of workers producing thermal clothing had nearly identical mean symptom scores for all body regions (fig 2 ). The workers at Tinn, and to some extent Rjukan, reported lower symptom scores in the head, neck, and shoulders, but the difference was not statistically significant. The two groups of workers performing sewing and welding operations in the production of offshore survival suits had symptom profiles similar to those producing thermal clothing, except that the welding group had significantly less problems with their lower arms consistent with the reduced strain on the arms for this work task (see Methods).

Figure 3 shows the location of symptoms in the left and right shoulders and lower arms for the production workers. Distribution of symptoms for the shoulders was symmetrical (fig $3 \mathrm{~A}$ ) whereas problems in the lower arms were biased towards the right arm (fig 3B). The symmetrical distribution of shoulder symptoms is consistent with the electromyograph load recordings, which showed static load patterns in both trapezius muscles.

It was reported in a separate publication of this study that production workers with a four to five hour working day on average recorded their first sick leave due to musculoskeletal illnesses about six months later than those on eight hour work schedules but this difference disappeared after the first few years for complaints in the shoulder and neck region. By contrast, differences for sick leaves with a complaint located to the low back appeared to last longer. ${ }^{15}$ Figure 4 shows symptom profiles for full time and part time production workers. The mean symptom score for the neck was somewhat lower for the part
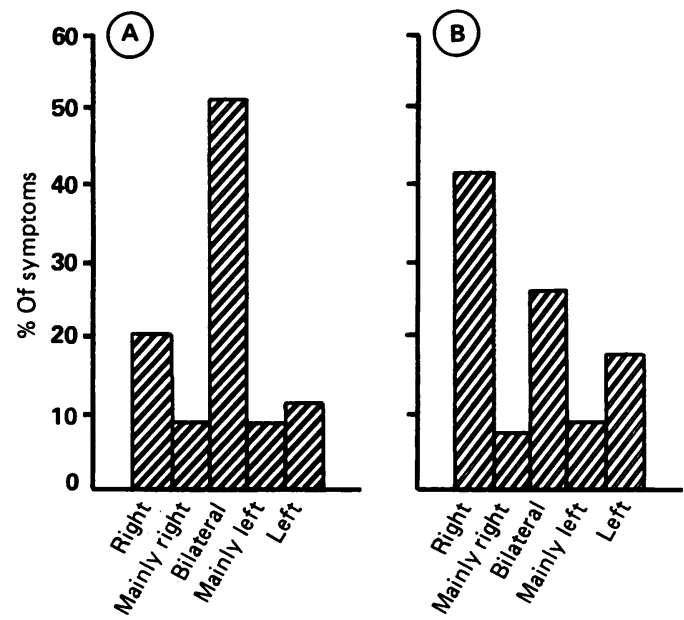

Figure 3 Distribution of symptoms of discomfort or pain on left and right shoulders $(A)$ and lower arms $(B)$. 


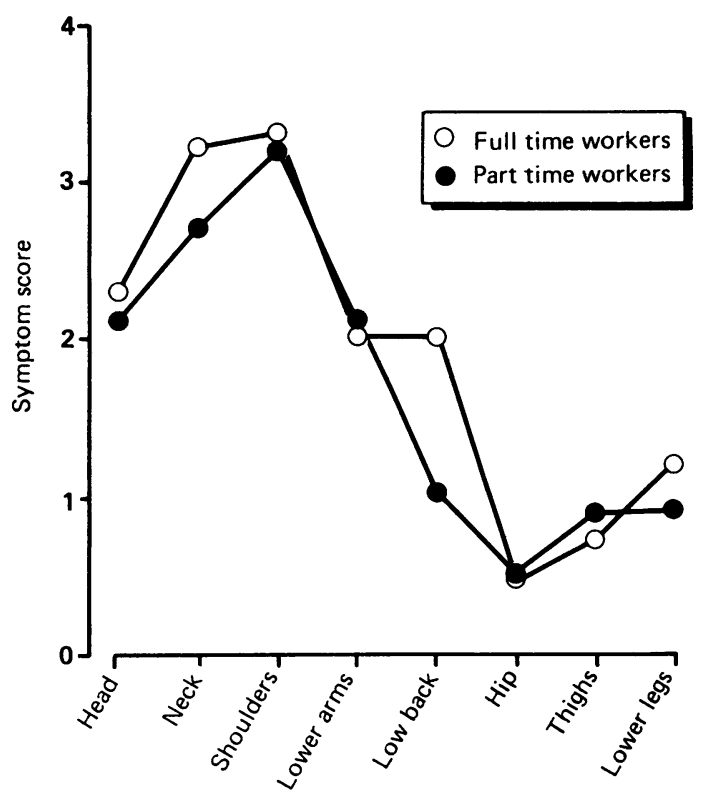

Figure 4 Mean symptom score at different body locations for production workers working full time (115 subjects) and part time (45 subjects).

time workers $(p=0.06)$ and significantly lower for symptoms in the low back, consistent with the sick leave analysis.

\section{SYMPTOMS OF PAIN AND DISCOMFORT AND}

INDIVIDUAL FACTORS

Workers who have suffered symptoms before employment may have established a health condition at the time of employment that makes them particularly susceptible to similar injuries at the workplace. Many workers shared this opinion with regard to their own situation, as only $49 \%$ of those with musculoskeletal symptoms at work and with similar experiences before employment believed that a clear link existed between symptoms and working conditions compared with $88 \%$ of those who had not experienced such symptoms previously.

Figure 5A shows the fraction of production workers reporting symptoms at different body locations before employment in the current work situation. Symptoms in the head and low back were most common, at about $30 \%$ each. About $15 \%$ of all subjects had experienced symptoms in the neck and shoulders, symptoms in knees and ankles were reported by $11 \%$ of all subjects, and symptoms in lower arms, hips, and thighs were infrequent (6 to $8 \%$ ). Figure 5B shows the mean symptom score for the different body regions of subjects with and without similar symptoms before employment. The same subject may contribute in both categories depending on the location of previous pain symptoms. In all body locations the mean current level of symptoms was higher when similar symptoms had occurred previously. Many production workers without such problems previously, however, had experienced considerable discomfort at work, particularly in the shoulders and neck.

Another a priori risk factor is age, as it is known that the incidence of musculoskeletal complaints increases with age in the general population. Figure 6 shows the mean symptom score for production workers less than 30 years, $30-40$ years, and more than 40 years old. The three upper body regions, which appear to be most affected by the working conditions, have the same symptom level at all age groups. A statistically significant negative correlation with age was found for the low back, possibly due to a "healthy worker" effect. Hips, thighs, and knee and ankles showed a positive correlation with age although this was not significant for the thighs $(\mathrm{p}=$ 0.07).

Personal psychological or psychosocial problems are frequently postulated to be a confounding factor in the development of muscle pain. Figure 7 shows the symptom profile of production workers considered to have psychological problems, and of production workers with no apparent sign of such problems. Those with psychological problems had a higher mean symptom score for the head and neck with no significant differences in other body regions.

In the limited material from production workers reporting on their general tendency to generate muscle tension, 29 definite negatives and 40 definite

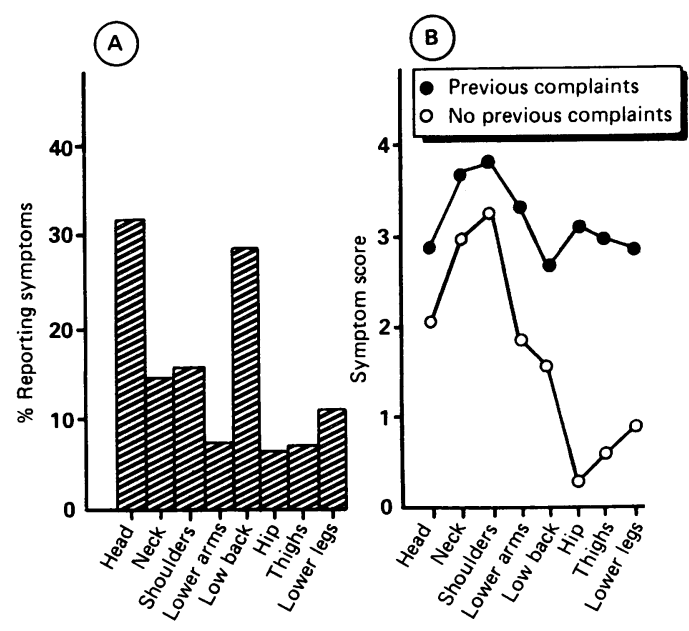

Figure 5 (A) Fraction of production workers reporting symptoms of discomfort or pain before present employment at different body locations. (B) Mean symptom score at different body locations for production workers with and without symptoms of discomfort or pain at the same body location before present employment. 


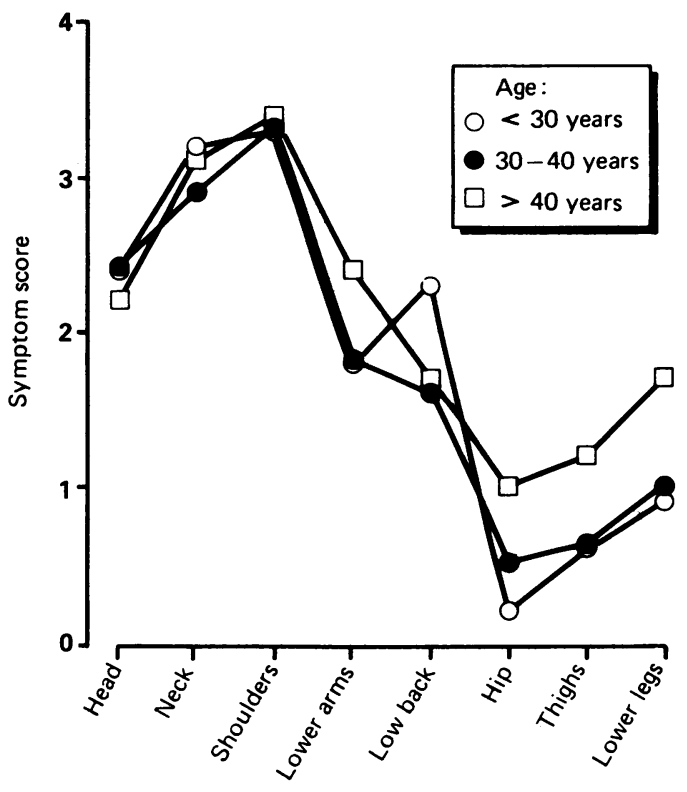

Figure 6 Mean symptom score at different body locations for three different age groups of production workers $(<30$ years, 84 subjects; $\geqslant 30-40$ years, 72 subjects; $>40$ years, 54 subjects).

positives were identified. The symptom score was significantly higher in the head, neck, and shoulders for those with a positive response. A possible interaction between this parameter and psychological problems was examined by cross tabulating neck symptoms as a function of positive or negative responses to the two parameters. Positive interactions were not indicated-that is, a raised level of neck symptoms was correlated with a positive response to either parameter with no further increase for those with positive responses to both parameters.

Table 2 presents a summary of the univariate analyses for the 210 production workers. Thus the large differences in level of symptoms in the upper body regions between production and office workers are not included. Apart from previous problems, which appeared to affect all body regions, only psychological problems and tendency of muscle tension showed a significant contribution to symptom level in the head and neck (muscle tension also in the shoulders). The only differential effect of the parameters of work task was the reduced symptom score of the low back for part time workers and of the lower arms for welders of survival suits. The correlation between symptoms in the lower arms and physical activity may be a type II error-namely, a false positive-as most of the activities described in the interview (jogging, swimming) would not strain the arms. Also, the initial hypothesis was that physical activity would reduce the level of musculoskeletal complaints at the work place. Low back symptoms showed a relatively complex relation with other variables.

The univariate analyses were used as a basis for a multilinear regression analysis. Individual factors (except physical activity) shown to correlate with symptom level at any body location on a univariate basis were included in the initial run for all body locations. Table 3 gives the results of the final analysis after elimination of those parameters not contributing to the variance in level of symptoms in the first analyses.

Low back and head symptoms retained a relatively complex relation with other factors, whereas symptoms at the other body regions only correlated with one or two parameters. Age showed a negative correlation with symptoms in the head and low back, and a positive correlation with symptoms in knee and ankles. The parameter "previous pain symptoms" correlated with present symptoms at all body regions except the neck, but the correlation was low for the shoulders and the lower arms. Working part time appeared helpful in reducing problems in the low back, and possibly also in the neck. Psychosocial (family) problems remained a risk factor for low back pain. The variance explained by the independent parameters (adjusted $\mathrm{r}^{2}$ ) varied between body regions and was highest for the lower body regions with low symptom score. By contrast, only $2-4 \%$ of total variance was explained by the individual parameters for neck, shoulders, and lower arms.

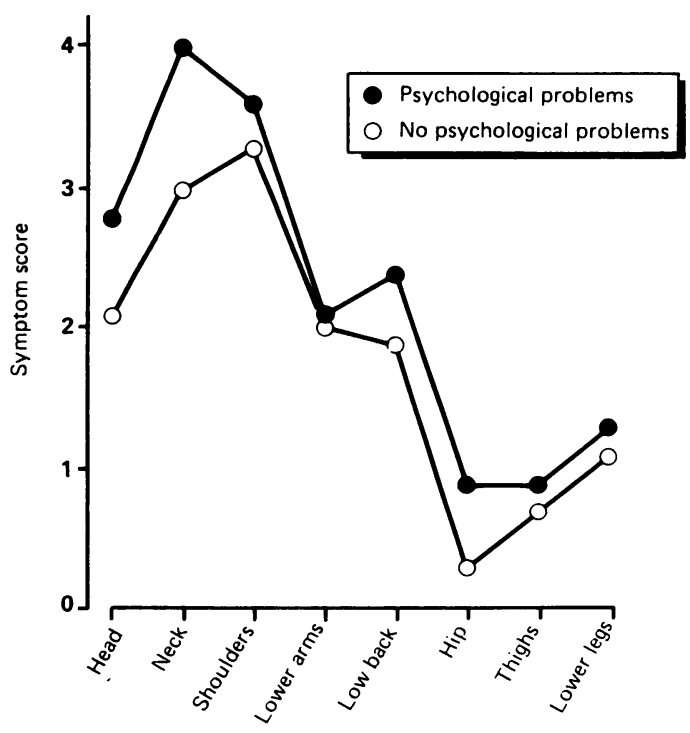

Figure 7 Mean symptom score at different body locations of production workers indicating ( 28 subjects) or not indicating ( 93 subjects) personal psychological problems. 
Table 2 Parameters correlating with pain/discomfort

\begin{tabular}{|c|c|c|}
\hline Body region & Variable & p Value \\
\hline Head & $\begin{array}{l}\text { Previous pain symptoms } \\
\text { Muscle tension } \\
\text { Psychological problems }\end{array}$ & $\begin{array}{r}0.001 \\
0.014 \\
0.031\end{array}$ \\
\hline Neck & $\begin{array}{l}\text { Previous pain symptoms } \\
\text { Psychological problems } \\
\text { Muscle tension }\end{array}$ & $\begin{array}{l}0.008 \\
0.010 \\
0.013\end{array}$ \\
\hline Shoulders, upper arms & $\begin{array}{l}\text { Previous pain symptoms } \\
\text { Muscle tension }\end{array}$ & $\begin{array}{l}0.017 \\
0.035\end{array}$ \\
\hline Lower arms & $\begin{array}{l}\text { Physical exercise } \\
\text { Previous pain symptoms } \\
\text { Welding work task }\end{array}$ & $\begin{array}{l}0.002 \\
0.005 \\
0.042\end{array}$ \\
\hline Low back & $\begin{array}{l}\text { Previous pain symptoms } \\
\text { Working hours } \\
\text { Family relationship } \\
\text { Children (negative) } \\
\text { Age (negative) }\end{array}$ & $\begin{array}{r}<0.001 \\
0.002 \\
0.029 \\
0.041 \\
0.047\end{array}$ \\
\hline Hip & $\begin{array}{l}\text { Previous pain symptoms } \\
\text { Age (positive) }\end{array}$ & $\begin{array}{l}<0.001 \\
<0.001\end{array}$ \\
\hline Thighs & Previous pain symptoms & $<0.001$ \\
\hline Knee and ankles & $\begin{array}{l}\text { Previous pain symptoms } \\
\text { Age (positive) }\end{array}$ & $\begin{array}{r}<0.001 \\
0.015\end{array}$ \\
\hline
\end{tabular}

Univariate analysis of variance for 210 production workers. All parameters resulting in $p \leqslant 0.05$ are included in the table.

Between 27 and $53 \%$ of the subjects reported a development towards worse symptoms in different body regions after they first appeared, with the highest percentages for complaints in the neck, shoulders, and arms. Between 3 and $16 \%$ reported improved symptom levels after the first episode of pain. The questions on symptoms at the interview were phrased in terms of symptoms throughout the working period, which would be variable. It was therefore not possible at the outset to calculate period prevalence. For the 84 to $97 \%$ of the subjects with aggravated or unchanged problems, however, the reported symptom score would also be representative of symptoms experienced during the last 12 months. Also, some subjects indicating an improved symptom level would have experienced this improvement during the past 12 months. Thus the symptom scores reported in this paper also represent an approximation of a 12 month period prevalence.

\section{Discussion}

This study confirms the results of other studies, which show a high rate of musculoskeletal complaints among sewing machine operators (see Introduction). A particular interest of the present study was the intersubject variation in symptom levels and the dependence on factors not a priori related to the work tasks. The increased symptom level of the upper body regions of the production workers relative to the office group, and the near identical symptom profiles of different groups of

Table 3 Multilinear symptom analysis

\begin{tabular}{|c|c|c|c|}
\hline Body region & Variable & Adjusted $r^{2}$ & p Value \\
\hline Head & $\begin{array}{l}\text { Previous pain symptoms } \\
\text { Muscle tension } \\
\text { Age (negative) } \\
\text { Psychological problems }\end{array}$ & $0 \cdot 10$ & $\begin{array}{r}<0.001 \\
0.035 \\
0.038 \\
0.052\end{array}$ \\
\hline Neck & $\begin{array}{l}\text { Psychological problems } \\
\text { Working hours }\end{array}$ & 0.04 & $\begin{array}{l}0.038 \\
0.055\end{array}$ \\
\hline Shoulders, upper arms & Previous pain symptoms & 0.02 & 0.041 \\
\hline Lower arms & Previous pain symptoms & 0.03 & 0.011 \\
\hline Low back & $\begin{array}{l}\text { Previous pain symptoms } \\
\text { Working hours } \\
\text { Age (negative) } \\
\text { Family relationship }\end{array}$ & $0 \cdot 19$ & $\begin{array}{r}<0.001 \\
0.001 \\
0.002 \\
0.012\end{array}$ \\
\hline Hip & Previous pain symptoms & 0.33 & $<0.001$ \\
\hline Thighs & Previous pain symptoms & $0 \cdot 18$ & $<0.001$ \\
\hline Knee and ankles & $\begin{array}{l}\text { Previous pain symptoms } \\
\text { Age (positive) }\end{array}$ & $0 \cdot 17$ & $\begin{array}{r}0.001 \\
0.025\end{array}$ \\
\hline
\end{tabular}

Multivariate linear regression analysis of pain symptoms at different body locations (dependent variable) $v$ previous pain symptoms, age, psychological problems, tendency of muscle tension, children, relationship to close family, and daily working hours (independent variables), based on 210 production workers. All parameters with $\mathrm{p}<0 \cdot 1$ are included in the table. 
production workers with similar work tasks, however, provide strong evidence for a dominant, work related aetiology in the development of these complaints. This study thereby serves as another indication of the inherent detrimental qualities of work situations with continuous arm movements, even when the static postural parameters are near optimal (see Methods).

The most important predictors of individual susceptibility to musculoskeletal complaints were previous episodes of similar pain syndromes, effects present in all body regions. The multivariate analysis indicated that previous pain symptoms contributed to a considerable fraction of total variance for symptoms in the lower extremities, but explained very little of the total variance of pain symptoms in the neck and shoulders. The reason for this result is presumably that the risk of developing work related musculoskeletal disorders in the neck and shoulders is high, regardless of latent problems present at the time of employment. This interpretation is supported by the results of a preliminary investigation in which a medical examination to identify signs of musculoskeletal complaints was carried out on 22 production workers in employment. Two years later little difference in regard to symptom level or need of medical attention was found between workers classified as risk or non-risk subjects when employed.

The only parameters apart from previous pain symptoms correlating with problems in the neck and shoulders in the univariate analysis were psychological problems (neck), and the self reported tendency of muscle tension (neck, shoulders). The effect of psychological state only accounted for $2 \%$ of total variance in symptom level for the neck and had no effect in the case of the shoulders according to the multivariate analysis. The low explanatory power can be due to our choice of parameter representation not pinpointing stronger underlying effects. Most studies of psychogenic muscle tension indicate, however, that such tension is of low intensity ${ }^{16}{ }^{17}$ and may therefore only result in a small additional tension component if static tension due to postural factors is already present in the muscle activity pattern. Accordingly, this parameter may appear as a much more important risk factor in populations where postural loading of the shoulder muscles is not a problem.

The development of muscle tension is associated with psychiatric disorders, ${ }^{18}$ with various psychological factors, ${ }^{19}$ with anxiety, ${ }^{20}{ }^{21}$ and with mentally demanding work tasks. ${ }^{162223}$ Muscle pain has been associated with parameters relating to the physiological state or trait. ${ }^{7}$ Primary fibromyalgia has been associated with specific psychological profiles in the Minnesota multiphasic personality inventory. ${ }^{24} \mathrm{~A}$ hypothesis to be tested in future is that the parameters "psychological problems" and "tendency of muscle tension" serve as indicators of the same underlying risk factor-namely, a subject dependent tendency of excess tension in the upper trunk muscles $^{1626}$ with a subsequent development of pain symptoms. The psychosocial work environment is another factor which may contribute to neck and shoulder pain through such a mechanism.

Both psychological problems and tendency to muscle tension correlated with symptoms in the head. This is consistent with the above hypothesis as head symptoms were delineated as tension headache in the dorsal aspects of the head. The negative correlation of head and low back symptoms with age may be explained as a "survival effect"-that is, a selection towards those who tolerate the work strain relatively well.

The low back was the only body region where symptoms correlated with our indicator of psychosocial life situation, relationship to close family. Psychosocial factors have also been previously implemented in the development of low back pain. ${ }^{27}{ }^{28}$ The reduction in low back pain of part time compared with full time workers is consistent with the results of the sick leave analysis. ${ }^{15}$

Many parameters often postulated to influence the susceptibility to musculoskeletal problems were not correlated with the level of discomfort at any body region. The economic situation, amount of physical exercise, marital state, children, living conditions, work load at home, and other activities outside work were not related to the level of musculoskeletal complaints (disregarding the correlation between physical activity and symptoms in the lower arms).

The results may be influenced by the choice of subjects or the system for measurement of these parameters. For instance, physical exercise was defined in terms of a certain level of condition training. Thus the negative result for this parameter does not rule out the possibility that a dedicated and well formulated training programme will be beneficial in preventing the development of musculoskeletal symptoms, but suggests that condition training does not have the general effect of protecting against occupational musculoskeletal complaints. Other individual parameters may show up as significant in larger populations, in populations with different life situations, or with different delineation of the parameters in the questionnaire.

Even so, parameters similar to those included in this study would probably not explain much of the total variance in the level of symptoms from the neck and shoulders. It is therefore not understood why there are "survivors," or symptom free workers in the face of severe work strain. Physiological factors at the workplace, like the number or pattern of micropauses in the muscle activity patterns ${ }^{26}$ may be important, but such hypotheses remain speculative at present. 
We acknowledge the support of employees and management of Helly-Hansen $\mathrm{A} / \mathrm{S}$ in carrying out this project. We are grateful to Mr Leiv Sandvik for advice on the use of statistical methods.

Requests for reprints to: $\mathrm{R} \mathrm{H}$ Westgaard, Division of Organisation and Work Science, the Norwegian Institute of Technology, Trondheim, Norway.

1 Wallace M, Buckle P. Ergonomic aspects of neck and upper limb disorders. International Review Ergonomics 1987;1:173-200.

2 Hagberg M, Wegman DH. Prevalence rates and odds ratios of shoulder-neck diseases in different occupational groups. $\mathrm{Br} \mathrm{J}$ Ind Med 1987;44:602-10.

3 Kilbom $\AA$. Isometric strength and occupational muscle disorders. Eur J Appl Physiol 1988;57:322-6.

4 Linton SJ, Kamwendo K. Risk factors in the psychosocial work environment for neck and shoulder pain in secretaries. JOccup Med 1989;31:609-13.

5 Karasek R, Gardell B, Lindell J. Work and non-work correlates of illness and behaviour in male and female Swedish white collar workers. Journal of Occupational Behaviour 1987;8: 187-207.

6 Kogstad O, Hartvig P. Psychiatric and social factors in rheumatological and physical medical disability. Tidsskr Nor Lageforen 1978;98:943-5 (In Norwegian).

7 Ursin H, Endresen IM, Ursin G. Psychological factors and selfreports of muscle pain. Eur J Appl Physiol 1988;57:282-90.

8 Westgaard RH, Jansen T. Individual and work related factors associated with symptoms of musculoskeletal complaints. I A quantitative registration system. $\mathrm{Br} J$ Ind Med 1992;49: 147-53.

9 Westgaard RH, Wærsted M, Jansen T, Aarảs A. Muscle load and illness associated with constrained body postures. In: Corlett N, Wilson J, Manenica I, eds. The ergonomics of working postures. London: Taylor and Francis, 1986:5-18.

10 Miyashita K, Shiomi S, Kasamatsu T, Itoh N, Iwata H. A study on occupational cervicobrachial disorder among female sewing machine operators in a small scale industry. Wakayama Medical Reports 1980;23:81-8.

11 Vihma T, Nurminen M, Mutanen P. Sewing-machine operators' work and musculo-skeletal complaints. Ergonomics 1982;25:295-8.

12 Punnett L, Robins JM, Wegman DH, Keyserling WM. Soft tissue disorders in the upper limbs of female garment workers. Scand J Work Environ Health 1985;11:417-25.

13 Blàder S, Barch Holst U, Danielsson S, Ferhm E, Kalpamaa M,
Leijon M, Lindh M, Markhede G, Mikaelsson B. Neck and shoulder complaints among sewing-machine operators. In: Buckle $\mathrm{P}$, ed. Musculoskeletal disorders at work. London: Taylor and Francis, 1987:110-1.

14 Sokas RK, Spiegelman MS, Wegman DH. Self-reported musculoskeletal complaints among garment workers. Am J Ind Med 1989;15:197-206.

15 Wrrsted M, Westgaard RH. Working hours as a risk factor in the development of musculoskeletal complaints. Ergonomics 1991;34:265-76.

16 Westgaard RH, Bjørklund RA. Generation of muscle tension additional to postural load. Ergonomics 1987;30:911-23.

17 Wrrsted M, Bjorklund RA, Westgaard RH. Shoulder muscle tension in a VDU-based task under reward and non-reward conditions. Proc Int Union Physiol Sci 1989;XVII:331.

18 Malmo RB, Shagass C. Physiologic study of symptom mechanisms in psychiatric patients under stress. Psychosom Med 1949;11:25-9.

19 Rimehaug T, Svebak S. Psychogenic muscle tension: the significance of motivation and negative affect in perceptualcognitive task performance. Int J Psychophysiol 1987;5: 97-106.

20 Sainsbury P, Gibson JG. Symptoms of anxiety and tension and the accompanying physiological changes in the muscular system. J Neurol Neurosurg Psychiatry 1954;37:216-24.

21 Malmo RB. On emotions, needs, and our archaic brain. New York: Holt, Rinehart, and Winston, 1975.

22 Shaw WA, Kline LH. A study of muscle action potentials during the attempted solution by children of problems of increasing difficulty. $J$ Exp Psychol 1947;37:146-58.

23 Eason RG, White CT. Muscular tension, effort, and tracking difficulty: Studies of parameters which affect tension level and performance efficiency. Perceptual Motor Skills 1961;12: 331-72.

24 Ahles TA, Yunus MB, Riley SD, Bradley JM, Masi AT. Psychological factors associated with primary fibromyalgia syndrome. Arthritis Rheum 1984;27:1101-6.

25 Wolfe F, Cathey MA, Kleinheksel SM, Amos SP, Hoffman RG Young DY, Hawley DJ. Psychological status in primary fibrositis and fibrositis associated with rheumatoid arthritis. $J$ Rheumatol 1984;11:500-6.

26 Veiersted KB, Westgaard RH, Andersen P. Pattern of muscle activity during stereotyped work and its relation to muscle pain. Int Arch Occup Environ Health 1990;62:31-41.

27 Biering-Sørensen F, Thomsen C. Medical, social and occupational history as risk indicators for low-back trouble in a general population. Spine 1986;11:720-5.

28 Biering-Sørensen F, Thomsen CE, Hilden J. Risk indicators for low back trouble. Scand J Rehabil Med 1989;21:151-7.

Accepted 17 June 1991 